\title{
Les Arts de la scène et la Révolution française, sous la direction de Philippe Bourdin et Gérard Loubinoux
}

\section{Lise Sabourin}

\section{(2) OpenEdition}

1 Journals

\section{Édition électronique}

URL : http://journals.openedition.org/studifrancesi/27696

DOI : 10.4000/studifrancesi.27696

ISSN : 2427-5856

Éditeur

Rosenberg \& Sellier

\section{Édition imprimée}

Date de publication : 31 décembre 2006

Pagination : 613

ISSN : 0039-2944

\section{Référence électronique}

Lise Sabourin, "Les Arts de la scène et la Révolution française, sous la direction de Philippe Bourdin et Gérard Loubinoux », Studi Francesi [En ligne], 150 (L | III) | 2006, mis en ligne le 30 novembre 2015, consulté le 08 novembre 2020. URL : http://journals.openedition.org/studifrancesi/27696 ; DOI : https://doi.org/10.4000/studifrancesi.27696

Ce document a été généré automatiquement le 8 novembre 2020.

\section{(c) $(1) \odot$}

Studi Francesi è distribuita con Licenza Creative Commons Attribuzione - Non commerciale - Non opere derivate 4.0 Internazionale. 


\title{
Les Arts de la scène et la Révolution française, sous la direction de Philippe Bourdin et Gérard Loubinoux
}

\author{
Lise Sabourin
}

\section{RÉFÉRENCE}

AV. VV., Les Arts de la scène et la Révolution française, sous la direction de Philippe BOURDIN et Gérard Loubinoux, P.U. de Clermont-Ferrand/ Musée de la Révolution française de Vizille, 2004, pp. 606.

1 Très largement ouvert à tous les arts de la scène - théâtre, danse, opéra, que ce soit dans les grandes institutions réorganisées en 1807-1808, les boulevards ou les foires cet ouvrage collectif veut appréhender la nature des échanges entre salle et scène tant sur la question des engagements politiques, des pratiques professionnelles ou amateurs, des écritures critiques et des réactions gouvernementales que de la nature du répertoire joué. Les deux collecteurs, respectivement historien culturel de la Révolution française et spécialiste de l'opéra aux XVIII ${ }^{e}$ et XIX ${ }^{\mathrm{e}}$ siècles, ont rassemblé les références de pièces de théâtre (pp. 557-579) et d'estampes (pp. 580-586, dont les illustrations des pp. 587-604 offrent quelques exemples) présentes au Centre de documentation-bibliothèque du Musée de la Révolution française. Ils ont fait appel à vingt-sept chercheurs qui offrent leurs contributions réparties en cinq temps: les institutions théâtrales parisiennes, les troupes et les salles en province et à l'étranger, les aléas du répertoire face au pouvoir, la part de l'imaginaire dans le spectacle, les postérités du théâtre révolutionnaire.

2 Dans la première section, essentiellement juridique et sociologique, Gregory S. BROWN (pp. 39-53) traite de la liberté théâtrale en 1789-90, Michèle SAJOus D’ORIA (pp. 55-72) du 
droit de construire des théâtres, David TROTт (pp. 73-92) du devenir du théâtre de foire et Alessandro DI PROFIO (pp. 93-116) des conséquences de la querelle des Bouffons sur l'opéra italien à Paris durant la Révolution, David chaillou (pp. 117-128) de l'Opéra de Paris sous le Consulat et l'Empire.

Puis un parcours géographique présente l'état du théâtre en province: en Rhône-etLoire en 1793-94 (Philippe BOURDIN, pp. 131-162), à Dijon de 1789 à 1810 (Clothilde TRÉHOREL, pp. 163-179), à Rouen durant la Révolution (Christine LE BOZEC, pp. 181-188), à Nantes (Karine LARGE, pp. 189-204), dans le Puy-de-Dôme sous le Consulat et l'Empire (Cyril tRIOLAIRE, pp. 205-234), avec une extension sur la présence du théâtre français à Hambourg (Karine RANCE, pp. 235-248).

4 La troisième partie est consacrée à la vie théâtrale: critique parisienne en 1791 (Michel BIARD, pp. 251-271), répertoire du Théâtre de la Nation, ex-Comédie-Française de 1789 à 1793 (Jacqueline RAZGONIKOFF, pp. 273-292), réunion des Théâtres Favart et Feydeau en 1801 (Patrick TAї̈B, pp. 339-366), présence sur scène des personnages de Brutus (Antoinette et Jean, ainsi que F. EHRARD, pp. 293-311) et d'Arlequin (Martin NADEAU, pp. 313-325), état du drame durant la Révolution (Françoise LE BORGNE, pp. 327-337).

5 Un autre mouvement s'élance vers l'imaginaire théâtral: sa place par rapport aux conventions (Marie-Laurence NETTER, pp. 369-380), la vision du militaire (Erica JOY MANNUCCI, pp. 381-394), le motif de la prison (Olivier BARA, pp. 395-418), la part de la danse dans le spectacle (Françoise DARTOIs, pp. 439-484) ou les figures privilégiées par Joseph Aude (Gérard Loubinoux, p. 419-438).

6 Enfin, la fortune littéraire de cette dramaturgie révolutionnaire est étudiée à court terme, par Jean-Luc CHAPPEY (pp. 487-507) sur la mobilisation des arts autour de Brumaire anVIII, par Irène TIEDER (pp. 545-554) dans son reflet scénographique de Marat et Sade, ou à longue portée, avec Patrick BERTHIER (pp. 509-524) à propos d'Anouilh et Rolland, et Michel BouRGUIGNON (pp. 525-544) chez Darté et Vilar.

7 L'introduction assumée par Philippe BouRDIN (pp. 9-36) rassemble les apports des trois journées d'étude de 1998, 1999 et 2001 ainsi regroupées dans ce volume, couronnées d'ailleurs par la représentation à Vizille en 2002 de Cadet Roussel ou Le Café des aveugles (1793) de Charles Tissot et Joseph Aude. Il démontre combien ce «moment révolutionnaire est apparu crucial et déterminant»(p. 9) grâce à la refonte des structures et des lieux théâtraux, à la recomposition et à la réflexion théorique ainsi libérées, à la réception nouvelle et parfois mouvementée du geste de l'acteur par un public élargi. 